\title{
The associations between domain-specific sedentary behaviours and dietary habits in European adults: a cross-sectional analysis of the SPOTLIGHT survey
}

Sofie Compernolle ${ }^{1}$ D, Katrien De Cocker ${ }^{1,2}$, Pedro J. Teixeira ${ }^{3}$, Jean-Michel Oppert ${ }^{4,5}$, Célina Roda ${ }^{4}$, Joreintje D. Mackenbach ${ }^{6}$, Jeroen Lakerveld ${ }^{6}$, Martin McKee ${ }^{7}$, Ketevan Glonti ${ }^{7}$, Harry Rutter ${ }^{7}$, Helga Bardos ${ }^{8}$, Greet Cardon ${ }^{1}$, Ilse De Bourdeaudhuij ${ }^{*}$ and on behalf of the WP3 SPOTLIGHT group

\begin{abstract}
Background: Sedentary behaviour has been associated with obesity and related chronic diseases. Disentangling the nature of this association is complicated due to interactions with other lifestyle factors, such as dietary habits, yet limited research has investigated the relation between domain-specific sedentary behaviours and dietary habits in adults. The aim of this paper was to examine the association between domain-specific sedentary behaviours and dietary habits in adults and to test the moderating effect of age and gender on this association.

Methods: A total of 6,037 participants from five urban regions in Europe completed an online survey, of which 6,001 were included in the analyses. Multilevel mixed-effects logistic regression analyses were used to examine main associations and interaction effects.

Results: All domain-specific sedentary behaviours, except transport-related sitting time, were significantly related to dietary habits. In general, having a higher sitting time was related to having less healthy dietary habits, especially for television viewing. Gender did not moderate any of the relations, and age was only a significant moderator in the relation between other leisure sitting time and alcohol consumption.

Conclusion: Domain-specific sitting behaviours were related to unhealthy dietary behaviours. However, the small effect sizes suggest that individual level behavioural interventions focusing on sedentary behaviour will not be sufficient to improve dietary habits. The fact that almost none of the associations were moderated by age or gender suggests that these associations, and possibly also the effects of interventions targeting both behaviours, may hold across age and gender groups.
\end{abstract}

Keywords: Sitting time, Eating behaviour, Obesity

\section{Background}

Sedentary behaviour, defined as any waking activity characterized by an energy expenditure of $\leq 1.5$ metabolic equivalents and a sitting or reclining posture [1], has increased considerably in countries at all levels of development [2-4]. This increase is mainly attributed to changes in transport, entertainment and workplace environments,

\footnotetext{
* Correspondence: Ilse.DeBourdeaudhuij@Ugent.be

'Department of Movement and Sport Sciences, Faculty of Medicine and Health Sciences, Ghent University, Watersportlaan 2, Ghent B-9000, Belgium

Full list of author information is available at the end of the article
}

and has been linked to increases in obesity and related chronic diseases $[5,6]$. Disentangling the nature of this association is complicated by interactions with other lifestyle factors, such as dietary habits $[7,8]$. In particular, it is hypothesized that the association between television viewing and obesity may be due to the increased snacking behaviour associated with television viewing, rather than the action of sitting in front of the television [7].

This hypothesis is derived from evidence for an association between television viewing and unhealthy dietary habits $[7,9,10]$. However, the available evidence is strong 
for children and adolescents, but limited for adults [7, 9]. Moreover, previous studies focused solely on television viewing, only one domain of sedentary behaviour. Other domains, including transport-related, work-related, and other leisure-time sedentary behaviour [11], have not to date been associated with dietary habits. Nevertheless, there is a need to gain insight into any potential associations between these domain-specific sedentary behaviours and dietary habits, as many adults spend a substantial amount of time sitting in contexts other than domestic television viewing [12-14].

Additionally, it may be that the association between television time and dietary habits does not apply to everyone. Research by Pearson et al. [7] suggests that two demographic characteristics may moderate the association, namely age and gender. However, here too, evidence in adults is limited [7].

To address these gaps in the evidence, the first aim of this study was to explore associations between domainspecific sedentary behaviours and dietary habits in adults. Second, it assessed whether any association differed by age and gender. A better understanding of these associations could help guide future health promotion interventions.

\section{Methods}

\section{Study design and sampling}

This study was part of the SPOTLIGHT project [15], which was established to increase and combine knowledge on the wide range of overweight and obesity-related determinants to support effective health promotion approaches. The study was conducted in five urban regions in Belgium, France, Hungary, the Netherlands and the United Kingdom. Sampling of neighbourhoods and recruitment of participants has been described in detail elsewhere [16]. Briefly, neighbourhood sampling was based on a combination of residential density and socioeconomic status (SES) data at the neighbourhood level. This resulted in four types of neighbourhoods: low SES/ low residential density, low SES/ high residential density, high SES/ low residential density and high SES/ high residential density. In each urban region, three neighbourhoods of each neighbourhood type were randomly sampled (ie 12 neighbourhoods per urban region, 60 neighbourhoods in total). The aim was to recruit at least 100 participants per neighbourhood (6,000 in total) with an anticipated response rate of around $10 \%$. As we expected lower response rates from participants in low SES neighbourhoods [17], we oversampled adults ( $\geq 18$ years) from low SES neighbourhoods (1200 adults per neighbourhood) relative to high SES neighbourhoods (800 adults per neighbourhood). Subsequently, this random sample of adult ( $\geq 18$ years) inhabitants was invited by letter to participate in an online survey. This letter included general information of the study (eg the purpose, duration, confidentiality and voluntary nature), as well as a personal respondent number. By entering this respondent number on the website, participants were directed to the online survey. On the first page of this online survey, general study information was repeated briefly, followed by an informed consent. After providing informed consent, participants could fill out the online survey, containing questions on demographics, neighbourhood perceptions, social environmental factors, health, motivations and barriers for healthy behaviour, obesity-related behaviours and weight and height. The study was approved by the corresponding local ethics committees of participating countries.

\section{Measures}

\section{Sedentary behaviours}

Domain-specific sedentary behaviours were assessed using the Marshall questionnaire [18]. This questionnaire evaluated the average time spent sedentary while travelling, working, watching television, using a computer and doing other leisure time activities on both weekdays and weekend days by asking the following question: "During the last seven days, please estimate how much time you usually spent sitting in each of the following activities on a weekday and a weekend day [18]." Subsequently, the five different domains were listed, and participants were asked to provide an estimate of the average time spent sitting per domain on a usual weekday/weekend day. Total sedentary time per domain was estimated by summing the weekday (multiplied by five) and weekend day (multiplied by two) minutes. The sum (minutes/week) was divided by 420 (as there are seven days per week, and 60 minutes per hour) to express mean domain-specific sedentary time in hours/ day. Marshall. et al. showed that the questionnaire has acceptable criterion validity, with highest validity coefficients found for sitting time at work and using a computer at home (Pearson correlation $r=0.69-0.74$ ) [18].

\section{Dietary habits}

Dietary habits were measured using single items from food frequency questionnaires by asking: 'How many times a week do you usually eat/drink 1) fruit, 2) vegetables, 3) sugar-sweetened beverages, 4) alcoholic beverages, 5) sweets and 6) fast food?'. Response options were coded as follows: $0.5=$ 'once a week or less', $2=$ '2 times a week', $3=$ ' 3 times a week', $4=$ ' 4 times a week', $5={ }^{\prime} 5$ times a week', 6 = ' 6 times a week', 7 = '7 times a week', 14 = 'twice a day', and $21=$ 'more than twice a day'.

\section{Socio-demographic variables, BMI and moderate-to- vigorous physical activities}

Socio-demographic variables included age, gender, employment status and level of education (higher vs. lower). Higher education was defined as completing tertiary education (ie college or university), and lower education was 
defined as everything below a tertiary education. Body mass index (BMI) was calculated by dividing self-reported weight in kilograms by the square of the self-reported height in meters, and moderate-to-vigorous physical activity in the last seven days was measured using items from the long version of the International Physical Activity Questionnaire [19].

\section{Statistical analyses}

Inspection of the raw dataset revealed that item nonresponse ranged from $<1 \%$ for gender to $32 \%$ for other leisure sitting time. Twenty imputed datasets were generated using the method of chained equations with predictive mean matching, as we assumed data were missing at random [20, 21]. Estimates from the multiple imputations were pooled using Rubin's rules to obtain a single set of results [22]. A sensitivity analysis was performed on the original non-imputed dataset.

As the assumption of normality was not met for any of the dietary habit variables, they were dichotomized at the median for analyses. This resulted in the following categories: high ( $\geq 7$ portions/week) and low fruit intake ( $<7$ portions/week), high ( $\geq 7$ portions/week) and low vegetables intake ( $<7$ portions/week), high ( $\geq 2$ glasses/ week) and low sugar-sweetened beverages consumption ( $<2$ glasses/week), high ( $>2$ glasses/week) and low alcohol consumption ( $\leq 2$ glasses/week), high ( $\geq 3$ portions/ week) and low sweets intake ( $<3$ portions/week), and high ( $>0.5$ portions/week) and low fast food intake $(\leq 0.5$ portions/week). The outcomes are defined as high consumption versus low consumption.

Two two-level (neighbourhood and individual) mixedeffects logistic regression analyses with random intercepts were first conducted for each dietary habit (=dependent variable): one model including all participants, to examine the influence of transport-related sitting time, television time, computer time and other leisure sitting time (Model 1 ), and another model limited to working participants, to examine the influence of work-related sitting time (Model 2). Secondly, the two-level mixed effects logistics regression analyses were repeated with addition of interaction terms of age and gender (moderators $x$ domain-specific sedentary behaviours). Concretely, ten separate regression models were fitted for each dietary habit; five models to assess the interaction with each sedentary behaviour and age (eg transport-related sedentary behaviour $\times$ age, television time $\times$ age...), and five models to assess the interaction with each sedentary behaviour and gender (eg transport-related sedentary behaviour $\times$ gender, television time $\times$ gender...). To examine the interaction with age, age was dichotomised at 65 years, as this is generally the age of retirement, and is accompanied by a considerable change in health behaviours $[23,24]$. Where there was a significant interaction effect, analyses were stratified by age group or gender. Variance inflation factors were calculated for each independent variable included in the first model, ranging from 1.07-1.15, revealing no multicollinearity [25]. All analyses were adjusted for a range of covariates, previously shown to be associated with sedentary behaviour $[10,26]$ or dietary habits [27-29], ie urban region, neighbourhood type, age, gender, level of education, BMI and total moderate-to-vigorous physical activity. All analyses were performed with $\mathrm{R}$ software, version 3.1.2 [30] and level of significance was set at a twosided $p$-value of 0.05 .

\section{Results}

\section{Sample characteristics}

A total of 6,037 (out of 55,893) individuals participated in the study between February and September 2014. The overall response rate was $10.8 \%$. The response rate for residents from low SES neighbourhoods was $9.6 \%$, and the response rate for residents from high SES neighbourhoods was $11.9 \%$ [31]. Thirty-six participants were excluded from the analyses, as they did not provide information on their residential address. In total, 6,001 subjects were included in the analyses (Table 1); mean age was 51.9 years $(\mathrm{SD}=$ 16.4), $56.0 \%$ of subjects were women, $53.5 \%$ were in the higher education category, and $54.7 \%$ were currently employed. The lowest values for minutes sitting per day were observed for transport-related sitting (mean [SD]: 1.4 [1.5] hours/day), while highest values were observed for sitting at work (4.3 [2.6] hours/day).

\section{Associations between domain-specific sedentary behaviours and dietary habits}

Table 2 presents the main associations of domainspecific sedentary behaviours (transport-related sitting time, work-related sitting time, television time, computer time and other leisure sitting time) with dietary habits (fruit intake, vegetables intake, sugar-sweetened beverages consumption, alcohol consumption, sweets intake and fast food intake). All domain-specific sedentary behaviours were significantly associated with one or more dietary habits, except transport-related sitting time.

Having a higher television time was associated with four unhealthy dietary habits, namely having a lower fruit and vegetables intake, and having a higher sugar-sweetened beverages and fast food consumption. For example, per one hour increase in television time, participants have $2 \%$ lower odds of having a high fruit intake ( $\geq 7$ portions/ week). Computer time was negatively associated with fruit intake and alcohol consumption. Sitting more during other leisure time activities (than watching television or using the computer) was associated with having a higher fruit, alcohol and fast food consumption. Work-related sitting time was negatively associated with fruit intake, and positively associated with alcohol consumption. 
Table 1 Socio-demographic characteristics, sedentary behaviours and dietary habits of the total sample

\begin{tabular}{|c|c|}
\hline Characteristics & $\begin{array}{l}\text { Total sample } \\
(n=6,001)\end{array}$ \\
\hline \multicolumn{2}{|l|}{ Socio-demographic characteristics } \\
\hline Age (years), mean (SD) & $51.9(16.4)$ \\
\hline \multicolumn{2}{|l|}{ Gender, n (\%) } \\
\hline Male & $2612(44.0)$ \\
\hline Female & $3329(56.0)$ \\
\hline \multicolumn{2}{|l|}{ Level of education, n (\%) } \\
\hline Lower & $2505(46.5)$ \\
\hline Higher & $2877(53.5)$ \\
\hline \multicolumn{2}{|l|}{ Employment status, n (\%) } \\
\hline Currently employed & $3267(54.7)$ \\
\hline Currently not employed & $2711(45.3)$ \\
\hline \multicolumn{2}{|l|}{ Household composition, n (\%) } \\
\hline One-person household & $1219(22.6)$ \\
\hline Two person household & $2124(39.3)$ \\
\hline Three-person household & $848(15.7)$ \\
\hline Four-person household & $792(14.7)$ \\
\hline Five-or more-person household & $420(7.7)$ \\
\hline \multicolumn{2}{|l|}{ Domain-specific sedentary behaviours } \\
\hline Transport-related sitting time (hours/day), mean (SD) & $1.4(1.5)$ \\
\hline Work-related sitting time (hours/day), mean (SD) ${ }^{a}$ & $4.3(2.6)$ \\
\hline Television time (hours/day), mean (SD) & $2.6(2.1)$ \\
\hline Computer time (hours/day), mean (SD) & $1.9(1.9)$ \\
\hline Other leisure sitting time (hours/day), mean (SD) & $1.5(1.7)$ \\
\hline \multicolumn{2}{|l|}{ Dietary habits } \\
\hline Fruit intake (times per week), median (Q1, Q3) & $7.0(4.0,7.0)$ \\
\hline Vegetables intake (times per week), median (Q1, Q3) & $7.0(5.0,7.0)$ \\
\hline $\begin{array}{l}\text { Sugar-sweetened beverages consumption (times per } \\
\text { week), median (Q1, Q3) }\end{array}$ & $2.0(0.5,6.0)$ \\
\hline Alcohol consumption (times per week), median (Q1, Q3) & $2.0(0.5,6.0)$ \\
\hline Sweets intake (times per week), median (Q1, Q3) & $3.0(0.5,6.0)$ \\
\hline Fast food intake (time per week), median (Q1, Q3) & $0.5(0.5,0.5)$ \\
\hline Body mass index $\left(\mathrm{kg} / \mathrm{m}^{2}\right)$, mean (SD) & $25.2(4.5)$ \\
\hline
\end{tabular}

$\mathrm{N}$ for some variables is reduced due to missing data

SD Standard deviation, Q1 Quartile 1, Q3 quartile 3

${ }^{a}$ The mean and standard deviation of work-related sitting time was only computed for participants who were employed at the time of the survey

\section{Moderating effects of gender and age group on the association between domain-specific sedentary behaviour and dietary habits}

Moderating effects of gender and age group are reported in Table 3. Gender did not moderate any of the relations between domain-specific sedentary behaviours and dietary habits. Age was only a significant moderator in the relation between other leisure sitting time and alcohol consumption. Stratified analyses by age group showed that a positive significant association between other leisure sitting time and alcohol consumption was found in adults aged below 65 years $(\operatorname{adj} . \mathrm{OR}=1.025,95 \% \mathrm{CI}=$ $1.015,1.036)$, whereas no significant association was found in adults older than 65 years (adj. OR $=0.992,95 \% \mathrm{CI}=$ $0.974,1.011)$.

\section{Discussion}

Our first aim was to determine whether there are associations between domain-specific sedentary behaviours and dietary habits in adults. After controlling for sociodemographic factors, BMI and physical activity, eleven significant associations were found, of which nine showed that higher levels of work or leisure time (ie television time, computer time and other leisure sitting time) sedentary behaviour were associated with less healthy dietary habits. This finding may be important given that clustering of unhealthy behaviours has been found to have synergistic effects on health, which implies that the combined effects are more harmful than those from the sum of the individual unhealthy behaviours [32]. However, although several statistically significant associations were found, they do not necessarily reflect meaningful associations. Both the large sample size of this study, which may have resulted in an over rejection of the null hypothesis, and the small effect sizes, call into question the clinical relevance of the significant sedentary behaviours and dietary habits associations. In view of this, the main focus of this discussion will be on the four associations that were significant at the .001 level.

These four associations all showed that television viewing was unfavourably related to dietary habits. This is noteworthy, as television time is only one of the five domain-specific behaviours that were included in this study. More concretely, spending more time watching television was related to less frequent consumption of fruit and vegetables, and more frequent consumption of sugar-sweetened beverages and fast food. These findings confirm previously reported results [33-36], and could be explained by disrupted habituation to food cues $[37,38]$ or by increased exposure to unhealthy food advertisements $[39,40]$. For example, Scully et al. reported that respondents were significantly more likely to eat fast foods for snacks at least once weekly if they usually watched commercial television for two or three hours/day compared to those who watched commercial television for less than two hours/day [40]. Food advertisements may not only contribute to increases in unhealthy dietary habits by promoting unhealthy food options, they may also contribute to a reduction in consumption of healthy foods, such as fruit and vegetables, through potentially misleading messages about the nutritional value of food items [41]. Furthermore, individual-level factors, such as attitudes and norms about healthy lifestyles, or a number of other 
Table 2 Main effects of domain-specific sedentary behaviours on dietary habits

\begin{tabular}{|c|c|c|c|c|c|c|}
\hline & Fruit intake & Vegetables intake & $\begin{array}{l}\text { Sugar-sweetened } \\
\text { beverages } \\
\text { consumption }\end{array}$ & $\begin{array}{l}\text { Alcohol } \\
\text { consumption }\end{array}$ & $\begin{array}{l}\text { Sweets } \\
\text { intake }\end{array}$ & $\begin{array}{l}\text { Fast food } \\
\text { intake }\end{array}$ \\
\hline & $\begin{array}{l}\text { Adj. OR } \\
(95 \% \mathrm{Cl})\end{array}$ & $\begin{array}{l}\text { Adj. OR } \\
\text { (95 \% Cl) }\end{array}$ & $\begin{array}{l}\text { Adj.OR } \\
(95 \% \mathrm{Cl})\end{array}$ & $\begin{array}{l}\text { Adj. OR } \\
(95 \% \text { Cl) }\end{array}$ & $\begin{array}{l}\text { Adj. OR } \\
(95 \% \mathrm{Cl})\end{array}$ & $\begin{array}{l}\text { Adj. OR } \\
(95 \% \mathrm{Cl})\end{array}$ \\
\hline \multicolumn{7}{|l|}{ Model 1} \\
\hline $\begin{array}{l}\text { Transport-related sitting } \\
\text { time (hours/day) }\end{array}$ & $1.004(0.994,1.014)$ & $1.000(0.991,1.010)$ & $1.003(0.991,1.010)$ & $1.000(0.989,1.011)$ & $0.997(0.987,1.007)$ & $0.997(0.993,1.002)$ \\
\hline $\begin{array}{l}\text { Television time } \\
\text { (hours/day) }\end{array}$ & $0.984(0.976,0.991)^{* * *}$ & $0.981(0.975,0.987)^{* * *}$ & $1.017(1.010,1.025)^{* * * *}$ & $1.004(0.996,1.011)$ & $1.005(0.997,1.014)$ & $1.007(1.003,1.011)^{* * *}$ \\
\hline $\begin{array}{l}\text { Computer time } \\
\text { (hours/day) }\end{array}$ & $0.992(0.982,0.998)^{*}$ & $0.995(0.987,1.002)$ & $0.994(0.985,1.002)$ & $0.988(0.980,0.997)^{* *}$ & $0.999(0.990,1.008)$ & $1.004(1.000,1.009)$ \\
\hline $\begin{array}{l}\text { Other leisure sitting } \\
\text { time (hours/day) }\end{array}$ & $1.010(1.001,1.020)^{*}$ & $1.004(0.994,1.014)$ & $0.998(0.989,1.008)$ & $1.014(1.005,1.023)^{* *}$ & $1.006(0.997,1.015)$ & $1.009(1.004,1.013)^{* *}$ \\
\hline \multicolumn{7}{|l|}{ Model 2} \\
\hline $\begin{array}{l}\text { Work-related sitting } \\
\text { time (hours/day) }\end{array}$ & $0.994(0.986,0.999)^{*}$ & $1.003(0.996,1.011)$ & $0.993(0.986,1.000)$ & $1.010(1.002,1.017)^{* *}$ & $0.994(0.987,1.002)$ & $0.999(0.995,1.003)$ \\
\hline
\end{tabular}

Outcome variables were dichotomized based on the median

All analyses were adjusted for urban region, neighbourhood type, age, educational level, gender, body mass index, and moderate-to-vigorous physical activity Adj. OR adjusted odds ratio, $95 \% \mathrm{Cl}$ confidence interval at $95 \%$

$p<0.001,{ }^{* *} p<0.01,{ }^{*} p<0.05$

aspects affecting motivation, may also partially explain these results. For example, results from Mata et al. [42] suggest the existence of specific motivational "spill-over" effects across health behaviours during lifestyle change. The many associations between television time and unhealthy dietary habits seem likely to explain, at least in part, the adverse impact of television time on obesity and related chronic diseases [43-45], and thus clarify the stronger negative influence of television time on health compared to total sedentary behaviour. In this way, results of this study also contribute to resolve the controversy surrounding the direct (ie the action of sitting in front of the television leads to obesity) or indirect (ie sitting in front of the television leads to obesity via dietary habits) influence of television time on obesity and related chronic diseases, by suggesting that the effects are rather indirect.

In contrast, associations with other sedentary behaviours are weaker, less clinically relevant, and less consistent. For example, computer time was related to both unhealthy and healthy dietary habits: spending more computer time was related to both eating fruit and drinking alcohol less frequently. Given the considerable difference between television and computer time on dietary habits, our findings support the importance of analysing these two behaviours separately, rather than using a summary construct such as 'screen time', used in some previous papers (eg [46-48]). Other leisure sitting time was associated with two unhealthy dietary habits: more frequent consumption of both alcohol and fast food. However, the association with alcohol consumption was only significant in adults aged below 65 years, which is consistent with the fact that alcohol consumption decreases with increasing age [49]. As far as we know, there are no studies on the association of other types of leisure sitting time on dietary habits. However, given that other leisure time activities form a heterogeneous grouping, including visiting restaurants, socializing with friends, or going to a pub, the positive association with alcohol consumption and fast food intake could be expected. Nevertheless, more research is needed to confirm these results. Finally, spending more time sitting for work was positively related to alcohol consumption and negatively related to fruit intake. A cross-sectional Australian study found that those who sat longer at work had greater psychological distress [50], itself plausibly associated with higher alcohol consumption [51]. However, evidence is lacking on both the direction of causality and generalizability. On the other hand, evidence of an association between sedentary behaviour and fruit intake has been conflicting. Contrary to our findings, Pereira et al. showed that higher sitting time at work was associated with higher fruit intake [52]. The reason for these inconsistent results is unclear; however, it might be that other characteristics, such as type of work, may have influenced the relationship.

The second aim of this study was to assess whether any association differed by age and gender, as previous studies showed mixed results concerning the moderating role of age and gender [7]. Our results did not provide evidence to support a potential moderating role of age or gender, given that only one significant moderating effect was found, ie age moderated the association between leisure sitting time and alcohol consumption. Consequently, most associations between domain-specific sedentary behaviour and dietary habits seem to be consistent across men and women, and across adults and older adults. 
Table 3 Interaction effects of gender and age group on the association between domain-specific sedentary behaviours and dietary intake

\begin{tabular}{|c|c|c|c|c|c|c|c|c|c|c|c|c|}
\hline \multirow{2}{*}{$\begin{array}{l}\text { Outcomes: } \\
\text { Interaction terms }\end{array}$} & \multicolumn{2}{|l|}{ Fruit intake } & \multicolumn{2}{|c|}{ Vegetables intake } & \multicolumn{2}{|c|}{$\begin{array}{l}\text { Sugar-sweetened } \\
\text { beverages } \\
\text { consumption }\end{array}$} & \multicolumn{2}{|l|}{$\begin{array}{l}\text { Alcohol } \\
\text { consumption }\end{array}$} & \multicolumn{2}{|l|}{$\begin{array}{l}\text { Sweets } \\
\text { intake }\end{array}$} & \multicolumn{2}{|l|}{$\begin{array}{l}\text { Fast food } \\
\text { intake }\end{array}$} \\
\hline & $\begin{array}{l}\text { Gender } \\
\text { Adj. OR } \\
(95 \% \text { Cl) }\end{array}$ & $\begin{array}{l}\text { Age } \\
\text { Adj. OR } \\
(95 \% \text { Cl) }\end{array}$ & $\begin{array}{l}\text { Gender } \\
\text { Adj. OR } \\
\text { (95\% Cl) }\end{array}$ & $\begin{array}{l}\text { Age } \\
\text { Adj. OR } \\
(95 \% \text { Cl) }\end{array}$ & $\begin{array}{l}\text { Gender } \\
\text { Adj. OR } \\
(95 \% \mathrm{Cl})\end{array}$ & $\begin{array}{l}\text { Age } \\
\text { Adj. OR } \\
(95 \% \text { Cl) }\end{array}$ & $\begin{array}{l}\text { Gender } \\
\text { Adj. OR } \\
(95 \% \text { Cl) }\end{array}$ & $\begin{array}{l}\text { Age } \\
\text { Adj. OR } \\
(95 \% \text { Cl) }\end{array}$ & $\begin{array}{l}\text { Gender } \\
\text { Adj. OR } \\
(95 \% \text { Cl) }\end{array}$ & $\begin{array}{l}\text { Age } \\
\text { Adj. OR } \\
\text { (95\% Cl) }\end{array}$ & $\begin{array}{l}\text { Gender } \\
\text { Adj. OR } \\
(95 \% \text { Cl) }\end{array}$ & $\begin{array}{l}\text { Age } \\
\text { Adj. OR } \\
(95 \% \text { Cl) }\end{array}$ \\
\hline \multicolumn{13}{|l|}{ Model 1} \\
\hline $\begin{array}{l}\text { Transport-related } \\
\text { sitting time } \\
\text { (hours/day) }\end{array}$ & $\begin{array}{l}0.992 \\
(0.973,1.012)\end{array}$ & $\begin{array}{l}1.005 \\
(0.985,1.025)\end{array}$ & $\begin{array}{l}1.003 \\
(0.985,1.021)\end{array}$ & $\begin{array}{l}1.008 \\
(0.987,1.030)\end{array}$ & $\begin{array}{l}0.998 \\
(0.979,1.017)\end{array}$ & $\begin{array}{l}1.011 \\
(0.988,1.035)\end{array}$ & $\begin{array}{l}0.999 \\
(0.981,1.007)\end{array}$ & $\begin{array}{l}1.012 \\
(0.990,1.034)\end{array}$ & $\begin{array}{l}0.998 \\
(0.978,1.018)\end{array}$ & $\begin{array}{l}1.001 \\
(0.978,1.024)\end{array}$ & $\begin{array}{l}1.004 \\
(0.994,1.013)\end{array}$ & $\begin{array}{l}0.999 \\
(0.989,1.010)\end{array}$ \\
\hline $\begin{array}{l}\text { Television time } \\
\text { (hours/day) }\end{array}$ & $\begin{array}{l}0.992 \\
(0.980,1.005)\end{array}$ & $\begin{array}{l}1.007 \\
(0.994,1.021)\end{array}$ & $\begin{array}{l}1.001 \\
(0.989,1.013)\end{array}$ & $\begin{array}{l}1.006 \\
(0.991,1.020)\end{array}$ & $\begin{array}{l}1.005 \\
(0.993,1.018)\end{array}$ & $\begin{array}{l}0.996 \\
(0.982,1.011)\end{array}$ & $\begin{array}{l}0.994 \\
(0.981,1.018)\end{array}$ & $\begin{array}{l}1.002 \\
(0.989,1.014)\end{array}$ & $\begin{array}{l}0.994 \\
(0.981,1.006)\end{array}$ & $\begin{array}{l}1.012 \\
(0.997,1.027)\end{array}$ & $\begin{array}{l}1.000 \\
(0.994,1.007)\end{array}$ & $\begin{array}{l}0.996 \\
(0.989,1.004)\end{array}$ \\
\hline $\begin{array}{l}\text { Computer time } \\
\text { (hours/day) }\end{array}$ & $\begin{array}{l}0.993 \\
(0.978,1.009)\end{array}$ & $\begin{array}{l}1.002 \\
(0.985,1.018)\end{array}$ & $\begin{array}{l}1.002 \\
(0.988,1.016)\end{array}$ & $\begin{array}{l}0.997 \\
(0.980,1.014)\end{array}$ & $\begin{array}{l}0.995 \\
(0.981,1.010)\end{array}$ & $\begin{array}{l}1.003 \\
(0.984,1.021)\end{array}$ & $\begin{array}{l}1.002 \\
(0.987,1.017)\end{array}$ & $\begin{array}{l}1.015 \\
(0.998,1.033)\end{array}$ & $\begin{array}{l}1.002 \\
(0.988,1.017)\end{array}$ & $\begin{array}{l}1.005 \\
(0.988,1.023)\end{array}$ & $\begin{array}{l}0.998 \\
(0.991,1.005)\end{array}$ & $\begin{array}{l}0.999 \\
(0.989,1.008)\end{array}$ \\
\hline $\begin{array}{l}\text { Other leisure } \\
\text { sitting time } \\
\text { (hours/day) }\end{array}$ & $\begin{array}{l}1.009 \\
(0.993,1.027)\end{array}$ & $\begin{array}{l}1.001 \\
(0.983,1.020)\end{array}$ & $\begin{array}{l}0.998 \\
(0.983,1.014)\end{array}$ & $\begin{array}{l}0.993 \\
(0.976,1.011)\end{array}$ & $\begin{array}{l}0.993 \\
(0.976,1.009)\end{array}$ & $\begin{array}{l}1.007 \\
(0.989,1.025)\end{array}$ & $\begin{array}{l}1.005 \\
(0.989,1.023)\end{array}$ & $\begin{array}{l}0.983 \\
(0.964,0.999)^{*}\end{array}$ & $\begin{array}{l}0.993 \\
(0.976,1.009)\end{array}$ & $\begin{array}{l}1.004 \\
(0.983,1.026)\end{array}$ & $\begin{array}{l}0.999 \\
(0.990,1.007)\end{array}$ & $\begin{array}{l}0.994 \\
(0.985,1.003)\end{array}$ \\
\hline \multicolumn{13}{|l|}{ Model 2} \\
\hline $\begin{array}{l}\text { Work-related } \\
\text { sitting time } \\
\text { (hours/day) }\end{array}$ & $\begin{array}{l}0.997 \\
(0.986,1.008)\end{array}$ & $\begin{array}{l}1.003 \\
(0.987,1.020)\end{array}$ & $\begin{array}{l}0.997 \\
(0.987,1.008)\end{array}$ & $\begin{array}{l}0.995 \\
(0.980,1.009)\end{array}$ & $\begin{array}{l}0.996 \\
(0.985,1.007)\end{array}$ & $\begin{array}{l}0.998 \\
(0.981,1.015)\end{array}$ & $\begin{array}{l}1.006 \\
(0.996,1.016)\end{array}$ & $\begin{array}{l}1.000 \\
(0.984,1.016)\end{array}$ & $\begin{array}{l}0.998 \\
(0.988,1.009)\end{array}$ & $\begin{array}{l}1.006 \\
(0.988,1.024)\end{array}$ & $\begin{array}{l}1.001 \\
(0.995,1.006)\end{array}$ & $\begin{array}{l}0.999 \\
(0.992,1.006)\end{array}$ \\
\hline
\end{tabular}

Outcome variables were dichotomized based on the median

All analyses were adjusted for urban region, neighbourhood type, age, educational level, gender, body mass index, and moderate-to-vigorous physical activity

Adj. OR Adjusted odds ratio, $95 \% \mathrm{Cl}$ confidence interval at $95 \%$

Adj. OR Adjust
${ }^{*} p<0.05$ 
The main strength of this study was its innovative nature, as this study was the first to link different domain-specific sedentary behaviours to dietary habits. Examining domain-specific sedentary behaviour is important, as specific associations may be masked when analysing total sedentary behaviour. A second strength was the large sample size, which ensures adequate power to identify associations. A final strength was that the study sample was recruited from five urban regions in different European countries, which increases the external validity of our findings to Europe.

Despite these strengths, some limitations affect the validity and generalizability of the results. Firstly, information on both domain-specific sedentary behaviours and dietary habits was self-reported and therefore prone to social desirability and recall biases. Moreover, dietary habits were measured using single items, which may have reduced the accuracy. As both the predictor variables, the outcomes and the confounders were self-reported, observed associations may be the result of correlated error. Future studies should use more precise dietary assessment with quantitative assessment of dietary intake, preferably in combination with objective measurement instruments for sedentary behaviour. These objective measurement instruments (eg accelerometers, or inclinometers [53]) should be combined with Global Positioning Systems and/or diaries to gain insight into domain-specific sedentary behaviours. Secondly, the cross-sectional study design does not allow for causal inferences between domainspecific sedentary behaviours and dietary habits. Finally, despite sending reminders, the response rate was relatively low, which may have resulted in a selection bias. Although there is a good representation of men (44\%) and women (56 \%), lower (46.4\%) and higher (53.6\%) educated individuals as well as younger (from age 18 years) and older (up to age 109 years) adults [31], it remains likely that generally more healthy people participated, suggesting that we may have underestimated domain-specific sedentary behavior and unhealthy dietary habits. Possible reasons for the low response rate include first the oversampling of low SES residents. Low SES residents have been shown to be less likely to participate in a health survey [17]. However, as we aimed to have a heterogeneous sample with as many low SES residents as high SES residents, we decided to oversample the former, which is likely to have led to a lower overall response rate. Secondly, with regard to the absence of an upper age limit, we know that there may be attrition in surveys where older people are less likely to be able to complete a survey due to, for example, limited cognitive function, or vision impairment [54]. In addition, the questionnaire was mainly administered online. Previous studies have indicated that Internet use drops off significantly after the age of 75 [55], also potentially contributing to a lower response rate. Thirdly, the survey was relatively long. Participants spend on average $25.1 \pm 12.4 \mathrm{~min}$ to complete the questionnaire, which contained 50 key questions on 30 pages. Finally, we recognize that, in an era of frequent opinion polls and market research, people may react to what they perceive as over-surveying (i.e. become fed up with surveys). Although each of these factors, on their own, may not have had a large impact, they all act to reduce the response rate so, in combination, the effect may be appreciable.

\section{Conclusion}

Domain-specific sitting behaviours are only weakly related to unhealthy dietary behaviours. This suggests that individual level behavioural interventions focusing on sedentary behaviour will not be sufficient to improve dietary habits. Nevertheless, large-scale multi-level interventions, affecting both individual and environmental factors, are required. If future intervention designers, however do decide to develop an individual behavioural intervention to prevent obesity and related chronic diseases, television time should be recommended as main target, as television time was the only domain of sedentary behaviour that was consistently related to unhealthy dietary habits. Our results also suggest a limited moderating role of age and no moderating role of gender in the association between domain-specific sedentary behaviour and dietary habits. The fact that almost none of the associations were moderated by age or gender suggests that these associations, and possibly also the effects of interventions targeting both behaviours, may largely hold across age and gender groups. However, more research is needed in adult populations to confirm the lack of moderating effects of socio-demographic factors on the association between domain-specific sedentary behaviour and dietary habits, as this was the first study to include interactions with age and gender in an adult population.

\section{Abbreviations}

95 \% Cl: Confidence interval at 95 \%; Adj. OR: Adjusted odds ratio; BMI: Body mass index; SES: Socioeconomic status

\section{Acknowledgements}

We would like to thank Hélène Charreire, Thierry Feuillet, and Maher BenRebah (Equipe de Recherche en Epidémiologie Nutritionnelle, Université Paris 13) for their contribution to WP3 of the SPOTLIGHT project.

\section{Funding}

This work is part of the SPOTLIGHT project funded by the Seventh Framework Programme (CORDISFP7) of the European Commission, HEALTH(FP7-HEALTH2011-two-stage), Grant agreement No.278186. The content of this article reflects only the authors' views and the European Commission is not liable for any use that may be made of the information contained therein.

Availability of data and materials

The data is not deposited in publicly available repositories due to the rules of the SPOTLIGHT consortium. For more information, please contact our data manager, Jeroen Lakerveld (je.lakerveld@vumc.nl). 


\section{Authors' contributions}

SC conceived of the idea for the manuscript, conducted the statistical analyses, interpreted the data and drafted the manuscript. SC, JDM, JL, JMO, KG, HR, HB, and IDB conducted the data collection. All authors read, provided feedback, and approved the final submitted version of the manuscript.

\section{Competing interest}

The authors declare that they have no competing interests.

\section{Consent for publication}

Not applicable.

\section{Ethics approval and consent to participate}

On the first page of this online survey, general study information was repeated briefly, followed by an informed consent. After providing informed consent, participants could fill out the online survey. The study was approved by the corresponding local ethics committees of participating countries. In Belgium, the study was approved by the ethics committee of Ghent University Hospital, in The Netherlands by the Medical Ethics Committee of the VU University Medical Center in Amsterdam, in Hungary by the Health Science Council, Scientific Research Ethic Committee, in France by the Commission Nationale de l'Informatique et des Libertés and in the UK by The London School of Hygiene \& Tropical Medicine Ethics Committee.

\section{Author details}

'Department of Movement and Sport Sciences, Faculty of Medicine and Health Sciences, Ghent University, Watersportlaan 2, Ghent B-9000, Belgium. ${ }^{2}$ Research Foundation Flanders (FWO), Brussels, Belgium. Interdisciplinary Center for the Study of Human Performance, Faculty of Human Kinetics, University of Lisbon, Lisbon, Portugal. ${ }^{4}$ Equipe de Recherche en Epidémiologie Nutritionnelle (EREN), Centre de Recherche en Epidémiologie et Statistiques, Inserm (U1153), Inra (U1125), Cnam, COMUE Sorbonne Paris Cité, Université Paris 13, F-93017 Bobigny, France. ${ }^{5}$ Department of Nutrition Pitié-Salpêtrière Hospital (AP-HP), Centre for Research on Human Nutrition lle-de-France (CRNH IdF), Institute of Cardiometabolism and Nutrition (ICAN), Université Pierre et Marie Curie-Paris 6, Paris, France. ${ }^{6}$ Department of Epidemiology \& Biostatistics, EMGO Institute for Health and Care Research, VU University Medical Center, Amsterdam, The Netherlands. ${ }^{7}$ ECOHOST-The Centre for Health and Social Change, London School of Hygiene and Tropical Medicine, London, UK. ${ }^{8}$ Department of Preventive Medicine, Faculty of Public Health, University of Debrecen, Debrecen, Hungary.

Received: 3 May 2016 Accepted: 23 September 2016

Published online: 06 October 2016

\section{References}

1. Sedentary Behaviour Research Network. Letter to the editor: Standardized use of the terms "sedentary" and "sedentary behaviours". Appl Physiol Nutr Metab. 2012;37:540-2.

2. Chau JY, Merom D, Grunseit A, Rissel C, Bauman AE, van der Ploeg HP, Chau J, Merom D, Grunseit A, Rissel C. Temporal trends in non-occupational sedentary behaviours from Australian Time Use Surveys 1992, 1997 and 2006. Int J Behav Nutr Phys Act. 2012;9:76.

3. Church TS, Thomas DM, Tudor-Locke C, Katzmarzyk PT, Earnest CP, Rodarte RQ, Martin CK, Blair SN, Bouchard C. Trends over 5 decades in US occupation-related physical activity and their associations with obesity. PLoS One. 2011;6:e19657.

4. Ng SW, Popkin B. Time use and physical activity: a shift away from movement across the globe. Obes Rev. 2012;13:659-80.

5. Hamilton MT, Hamilton DG, Zderic TW. Role of low energy expenditure and sitting in obesity, metabolic syndrome, type 2 diabetes, and cardiovascular disease. Diabetes. 2007:56:2655-67.

6. Biddle SJ. Sedentary behavior. Am J Prev Med. 2007;33:502-4.

7. Pearson N, Biddle SJ. Sedentary behavior and dietary intake in children, adolescents, and adults: a systematic review. Am J Prev Med. 2011;41:178-88.

8. de Rezende LFM, Lopes MR, Rey-López JP, Matsudo VKR, do Carmo Luiz O. Sedentary behavior and health outcomes: an overview of systematic reviews. PLoS One. 2014;21:8.

9. Hobbs M, Pearson N, Foster PJ, Biddle SJ. Sedentary behaviour and diet across the lifespan: an updated systematic review. Br J Sports Med. 2014 doi:10.1136/bjsports-2014-093754.
10. Rhodes RE, Rachel SM, Temmel CP. A systematic review. Am J Prev Med 2012;42:e3-28.

11. Chastin SFM, Schwarz U, Skelton DA. Development of a consensus taxonomy of sedentary behaviors (SIT): report of delphi round 1. PLoS One. 2013:8: e82313.

12. Brown $W$, Miller $Y$, Miller R. Sitting time and work patterns as indicators of overweight and obesity in Australian adults. Int J Obes (Lond). 2003;27: 1340-6.

13. Mummery WK, Schofield GM, Steele R, Eakin EG, Brown WJ. Occupational sitting time and overweight and obesity in Australian workers. Am J Prev Med. 2005;29:91-7.

14. Chau JY, van der Ploeg HP, Dunn S, Kurko J, Bauman AE. A tool for measuring workers' sitting time by domain: the Workforce Sitting Questionnaire. Br J Sports Med. 2011. doi:10.1136/bjsports-2011-090214.

15. Lakerveld J, Brug J, Bot S, Teixeira P, Rutter H, Woodward E, Samdal O, Stockley L, De Bourdeaudhuij I, van Assema P, et al. Sustainable prevention of obesity through integrated strategies: The SPOTLIGHT project's conceptual framework and design. BMC Public Health. 2012;12:793.

16. Lakerveld J, Ben-Rebah M, Mackenbach JD, Charreire H, Compernolle S, Glonti K, Bardos H, Nijpels G, Rutter H, De Bourdeaudhuij I, et al:: Obesityrelated behaviours and $\mathrm{BMI}$ in five urban regions across Europe: sampling design and results from the SPOTLIGHT cross-sectional survey. In press.

17. Demarest S, Van der Heyden J, Charafeddine R, Tafforeau J, Van Oyen H, Van Hal G. Socio-economic differences in participation of households in a Belgian national health survey. Eur J Public Health. 2012. doi:10.1093/eur pub/cks158.

18. Marshall AL, Miller YD, Burton NW, Brown WJ. Measuring total and domainspecific sitting: a study of reliability and validity. Med Sci Sports Exerc. 2010; 42:1094-102.

19. Craig CL, Marshall AL, Sjostrom M, Bauman AE, Booth ML, Ainsworth BE, Pratt M, Ekelund U, Yngve A, Sallis JF, Oja P. International physical activity questionnaire: 12-country reliability and validity. Med Sci Sports Exerc. 2003; 35:1381-95.

20. Graham JW, Olchowski AE, Gilreath TD. How many imputations are really needed? Some practical clarifications of multiple imputation theory. Prev Sci. 2007;8:206-13.

21. White $\mathbb{R}$, Royston P, Wood AM. Multiple imputation using chained equations: issues and guidance for practice. Stat Med. 2011;30:377-99.

22. Rubin DB. Multiple imputation for nonresponse in surveys. New York: John Wiley \& Sons; 2004

23. Touvier M, Bertrais S, Charreire H, Vergnaud A-C, Hercberg S, Oppert J-M. Changes in leisure-time physical activity and sedentary behaviour at retirement: a prospective study in middle-aged French subjects. Int J Behav Nutr Phys Act. 2010;7:1186

24. Barnett I, van Sluijs EM, Ogilvie D. Physical activity and transitioning to retirement: a systematic review. Am J Prev Med. 2012;43:329-36.

25. Bowerman BL, O'Connell RT. Linear statistical models: an applied approach. Montgomery: Duxbury; 2000.

26. Koohsari MJ, Sugiyama T, Sahlqvist S, Mavoa S, Hadgraft N, Owen N Neighborhood environmental attributes and adults' sedentary behaviors: review and research agenda. Prev Med. 2015;77:141-9.

27. Evans A, Booth $\mathrm{H}$, Cashel K. Sociodemographic determinants of energy, fat and dietary fibre intake in Australian adults. Public Health Nutr. 2000;3:67-75.

28. De Irala-Estevez J, Groth M, Johansson L, Oltersdorf U, Prattala R, MartínezGonzález MA. A systematic review of socio-economic differences in food habits in Europe: consumption of fruit and vegetables. Eur J Clin Nutr. 2000; 54:706-14.

29. Sweeting $H$, Anderson A, West P. Socio-demographic correlates of dietary habits in mid to late adolescence. Eur J Clin Nutr. 1994;48:736-48.

30. R Development Core Team. R: A language and environment for statistical computing. Vienna: R Foundation for Statistical Computing; 2012.

31. Lakerveld J, Ben Rebah M, Mackenbach JD, Charreire H, Compernolle S, Glonti K, Bardos H, Rutter H, De Bourdeaudhuij I, Brug J, Oppert J-M. Obesity-related behaviours and BMI in five urban regions across Europe: sampling design and results from the SPOTLIGHT cross-sectional survey. BMJ Open. 2015;5.

32. De Groot LC, Verheijden MW, De Henauw S, Schroll M, Van Staveren WA, Investigators S. Lifestyle, nutritional status, health, and mortality in elderly people across Europe: a review of the longitudinal results of the SENECA study. J Gerontol A Biol Sci Med Sci. 2004;59:1277-84.

33. Cleland V, Schmidt MD, Dwyer T. Television viewing and abdominal obesity in young adults: is the association mediated by food and beverage consumption 
during viewing time or reduced leisure-time physical activity? Am J Clin Nutr. 2008;87:1148-55.

34. Rehm CD, Matte TD, Van Wye G, Young C, Frieden TR. Demographic and behavioral factors associated with daily sugar-sweetened soda consumption in New York City adults. J Urban Health. 2008;85:375-85.

35. Bowman SA. Television-viewing characteristics of adults: correlations to eating practices and overweight and health status. Prev Chronic Dis. 2006;3:A38.

36. Charreire H, Kesse-Guyot E, Bertrais S, Simon C, Chaix B, Weber C, Touvier M, Galan P, Hercberg S, Oppert J-M. Associations between dietary patterns, physical activity (leisure-time and occupational) and television viewing in middle-aged French adults. Br J Nutr. 2011;105:902-10.

37. Temple JL, Giacomelli AM, Kent KM, Roemmich JN, Epstein LH. Television watching increases motivated responding for food and energy intake in children. Am J Clin Nutr. 2007;85:355-61.

38. Epstein $L H$, Temple JL, Roemmich JN, Bouton ME. Habituation as a determinant of human food intake. Psychol Rev. 2009;116:384.

39. Harris JL, Bargh JA, Brownell KD. Priming effects of television food advertising on eating behavior. Health Psychol. 2009;28:404.

40. Scully M, Dixon H, Wakefield M. Association between commercial television exposure and fast-food consumption among adults. Public Health Nutr. 2009;12:105-10.

41. Boynton-Jarrett R, Thomas TN, Peterson KE, Wiecha J, Sobol AM, Gortmake SL. Impact of television viewing patterns on fruit and vegetable consumption among adolescents. Pediatrics. 2003;112:1321-6.

42. Mata J, Silva MN, Vieira PN, Carraça EV, Andrade AM, Coutinho SR, Sardinha LB, Teixeira PJ. Motivational "spill-over" during weight control: Increased selfdetermination and exercise intrinsic motivation predict eating self-regulation. Health Psychol. 2009;28:709.

43. Salmon J, Bauman A, Crawford D, Timperio A, Owen N. The association between television viewing and overweight among Australian adults participating in varying levels of leisure-time physical activity. Int J Obes Relat Metab Disord. 2000;24:600-6.

44. Dunstan D, Barr E, Healy G, Salmon J, Shaw J, Balkau B, Magliano D, Cameron A, Zimmet $P$, Owen N. Television viewing time and mortality the australian diabetes, obesity and lifestyle study (AusDiab). Circulation. 2010;121:384-91.

45. Bertrais S, Beyeme-Ondoua JP, Czernichow S, Galan P, Hercberg S, Oppert $J \mathrm{M}$. Sedentary behaviors, physical activity, and metabolic syndrome in middle-aged French subjects. Obes Res. 2005;13:936-44.

46. Banks E, Jorm L, Rogers K, Clements M, Bauman A. Screen-time, obesity, ageing and disability: findings from 91266 participants in the 45 and Up Study. Public Health Nutr. 2011;14:34-43.

47. Boone JE, Gordon-Larsen P, Adair LS, Popkin BM. Screen time and physical activity during adolescence: longitudinal effects on obesity in young adulthood. Int J Behav Nutr Phys Act. 2007;4:26.

48. Hume C, Singh A, Brug J, Mechelen WW, Chinapaw M. Dose-response associations between screen time and overweight among youth. Int $J$ Pediatr Obes. 2009:4:61-4.

49. Yuan Y, Yen ST. Alcohol consumption by individuals in the United States: a sample selection approach. Applied Economics Letters. 2012;19:1353-8.

50. Kilpatrick M, Sanderson K, Blizzard L, Teale B, Venn A. Cross-sectional associations between sitting at work and psychological distress: reducing sitting time may benefit mental health. Ment Health and Phys Act. 2013;6:103-9.

51. Vasse R, Nijhuis F, Kok G. Associations between work stress, alcohol consumption and sickness absence. Addiction. 1998;93:231-41.

52. Pereira SP, Ki M, Power C. Sedentary behaviour and biomarkers for cardiovascular disease and diabetes in mid-life: the role of television-viewing and sitting at work. PLoS One. 2012;7, e31132

53. Atkin AJ, Gorely T, Clemes SA, Yates T, Edwardson C, Brage S, Salmon J, Marshall SJ, Biddle SJ. Methods of measurement in epidemiology: sedentary behaviour. Int J Epidemiol. 2012;41:1460-71.

54. Rubin GS, Roche KB, Prasada-Rao P, Fried LP. Visual impairment and disability in older adults. Optom Vis Sci. 1994;71:750-60.

55. Zickuhr K, Madden M. Older adults and internet use. Pew Internet American Life Project. 2012;6.

\section{Submit your next manuscript to BioMed Central and we will help you at every step:}

- We accept pre-submission inquiries

- Our selector tool helps you to find the most relevant journal

- We provide round the clock customer support

- Convenient online submission

- Thorough peer review

- Inclusion in PubMed and all major indexing services

- Maximum visibility for your research

Submit your manuscript at www.biomedcentral.com/submit
Biomed Central 